\title{
Enteropatógenos associados a enterocolite em potros: Aspectos epidemiológicos, clínicos e métodos de diagnóstico
}

\author{
Enteropathogens associated with enterocoliti in foals: Epidemiological, clinical aspects and \\ diagnostic methods \\ Enteropatógenos asociados a enterocoliti en potros: Aspectos epidemiológicos, clínicos y métodos de \\ diagnóstico
}

\section{Resumo}

As enterocolites estão entre as afecções que mais acometem potros em sistemas de criações de equinos em todo o mundo. É estimado que até $80 \%$ dos potros nos primeiros seis meses de vida são acometidos por pelo menos um episódio de diarreia, em sua grande maioria episódios leves e transitórios, entretanto, os custos com o tratamento e a taxa de mortalidade que esta afecção pode gerar são impactantes para criadores e proprietários. O objetivo desta revisão é descrever os aspectos epidemiológicos, clínicos e métodos de diagnóstico dos principais enteropatógenos bacterianos, virais e parasitários envolvidos em episódios de diarreia em potros do nascimento aos 8 meses de vida. Foram utilizados artigos disponíveis nas plataformas Mendeley, MEDLINE, pubMed, SciELO. Entre os principais enteropatógenos causadores de diarreia em potros, podemos destacar as infecções causadas por Salmonella spp., Escherichia coli, Rhodococcus equi, Clostridium perfringens, Clostridium difficile, Lawsonia intracellularis, Rotavírus, Coronavírus e helmintos. A identificação de potros de risco e a implementação de protocolos terapêuticos com base nos exames complementares e identificação do agente etiológico são de grande importância para o sucesso no tratamento, controle e implementação de métodos de profilaxia nos sistemas de criação.

Palavras-chave: Enterites; Enteropatógenos; Equino; Afecções entéricas.

\begin{abstract}
Enterocolitis is among the conditions that most affect foals in horse breeding systems worldwide. It is estimated that up to $80 \%$ of foals in the first six months of life are affected by at least one episode of diarrhea, mostly mild and transient episodes, however, the costs of treatment and the mortality rate that this condition can generate are impacting for breeders and owners. The aim of this review is to describe the epidemiological, clinical and diagnostic methods of the main bacterial, viral and parasitic enteropathogens involved in episodes of diarrhea in foals from birth to 8 months of age. Articles available on the Mendeley, MEDLINE, pubMed and SciELO platforms were used. Among the main enteropathogens causing diarrhea in foals, we can highlight infections caused by Salmonella spp., Escherichia coli, Rhodococcus equi, Clostridium perfringens, Clostridium difficile, Lawsonia intracellularis, Rotavirus, Coronavirus and helminths. The identification of high-risk foals and the implementation of therapeutic protocols based on complementary tests and identification of the etiological agent are of great importance for the success in the treatment, control and implementation of prophylaxis methods in the breeding systems.
\end{abstract}


Keywords: Enteritis; Enteropathogens; Equine; Enteric disorders.

\section{Resumen}

La Enterocolites es una de las condiciones que más afectan a los potros en los sistemas de reproducción equina en todo el mundo. Se estima que hasta un $80 \%$ de los potros en los primeros seis meses de vida se ven afectados por al menos un episodio de diarrea, la mayoría de los cuales son episodios leves y transitorios, sin embargo, los costos del tratamiento y la tasa de mortalidad que esta condición puede generar son impactantes para creadores y propietarios. El propósito de esta revisión es describir los métodos epidemiológicos, clínicos y de diagnóstico de los principales enteropatógenos bacterianos, virales y parasitarios implicados en los episodios de diarrea en potros desde el nacimiento hasta los 8 meses de edad. Se utilizaron los artículos disponibles en las plataformas Mendeley, MEDLINE, pubMed y SciELO. Entre los principales enteropatógenos que causan diarrea en los potros, podemos destacar las infecciones causadas por Salmonella spp., Escherichia coli, Rhodococcus equi, Clostridium perfringens, Clostridium difficile, Lawsonia intracellularis, Rotavirus, Coronavirus y helmintos. La identificación de potros de alto riesgo y la implementación de protocolos terapéuticos basados en pruebas complementarias e identificación del agente etiológico son de gran importancia para el éxito en el tratamiento, control e implementación de métodos de profilaxis en los sistemas de cría.

Palabras clave: Enteritis; Enteropatógenos; Equino; Trastornos entéricos.

\section{Introdução}

Apesar do constante desenvolvimento cientifico e tecnológico na criação de equinos, as doenças no sistema de criação de potros ainda são um grande desafio para médicos veterinários e criadores, pois apresentam um significativo impacto no crescimento e desenvolvimento desses indivíduos. Estudos epidemiológicos apontam as enterocolites como a segunda doença mais incidente nos sistemas de criação de potros, atrás apenas das afecções respiratórias (Cohen, 1994), sendo estimado que até 80\% dos potros nos primeiros seis meses de vida são acometidos por pelo menos um episódio de diarreia (Harris et al., 2012).

A diarreia é caracterizada pela alteração na consistência e frequência de defecação e pode se manifestar de forma leve e auto limitante ou em casos mais graves, com o desenvolvimento de enterocolite associada a grave comprometimento sistêmico (Mallicote et al., 2012). A fisiopatologia é multifatorial e pode incluir alterações na motilidade gastroentérica, má digestão, má absorção, hipersecreção e inflamação, que podem ser desencadeadas predominantemente pela ação de vírus, bactérias e parasitas (Magdesian et al., 2006). Por esse motivo, é necessário identificar o paciente de risco e estabelecer um plano terapêutico a partir de exames complementares e da identificação do agente etiológico (Mallicote et al., 2012). Apesar disso, o diagnóstico final pode ser desafiante, pois alguns agentes com potencial patogênico vivem em simbiose na microbiota intestinal de potros, e por este motivo, a sua identificação em amostras fecais pode não estar associada ao contexto clínico do indivíduo.

No Brasil, Olivo e colaboradores em 2016 destacaram os mecanismos de coinfecções entéricas e identificaram os principais fatores de virulência de alguns agentes, ainda assim, estudos de prevalência dos principais patógenos associados a infecções entéricas em potros são limitados. O objetivo desta revisão é descrever os aspectos epidemiológicos, clínicos e os métodos de diagnóstico para os principais enteropatógenos causadores de diarreia em potros do nascimento aos 8 meses de vida.

\section{Metodologia}

Este estudo é composto de uma revisão de literatura qualitativa como ferramenta de metodologia de pesquisa científica (Pereira et al., 2018), abordando os principais aspectos epidemiológicos, clínicos e métodos de diagnóstico para os principais enteropatógenos causadores de diarreia em potros do nascimento aos 8 meses de vida. Para a realização desta revisão foram selecionados artigos utilizando as principais bases de dados, entre as quais, as plataformas Mendeley, MEDLINE, pubMed, SciELO e livros. 


\section{Enteropatógenos causadores de diarreia em potros}

\subsection{Salmonella spp.}

A Salmonella é uma bactéria bastonete Gram negativa, anaeróbica facultativa e associada a distúrbios entéricos e/ou sistêmicos em animais e humanos (Slovis, 2011). A taxonomia do gênero Salmonella aceita nos últimos anos descreve a divisão em duas espécies, $S$. bongori e $S$. enterica, das quais a última abrange as principais subespécies e sorotipos patogênicos para animais e humanos. A S. enterica possui seis subespécies com mais de 2000 sorovares potencialmente patogênicos, sendo que a maioria dos casos clínicos estão associados a Salmonella enterica subsp enterica (Traub-Dargatz \& Besser, 2007). Em equinos, os sorovares frequentemente isolado em episódios de diarreia são a Salmonela Typhimurium, Newport, Anatum e Agona (Traub-Dargatz \& Besser, 2007).

A Salmonella pode ser identificada na microbiota entérica de potros com e sem sinais entérico e, quando associada a doença clínica geralmente afeta potros entre 12 horas a 4 meses de vida (Slovis, 2011). A sepse pode ocorrer simultaneamente com a diarreia, devido a invasividade e o potencial de translocação da barreira intestinal comprometida (Magdesian, 2006). A rota de transmissão da Salmonella é fecal-oral, ocorrendo pelo consumo de água e alimentos contaminados, contato com animais e ambientes infectados ou pelo hábito de coprofagia manifestado por potros jovens (Slovis, 2011). Além disso, a égua progenitora pode ser portadora assintomática da Salmonella e potencial fonte de contaminação ao potro (Magdesian, 2006; Slovis 2011). A permanência da salmonella no ambiente depende do sorotipo, teor de umidade e condições de temperatura (Hernandez et al., 2014). Estudos em bovinos revelaram que o agente pode persistir por até 5 anos em matéria fecal seca (Gray \& Fedorka-Cray, 2001).

No intestino, a salmonella invade os enterócitos, desencadeando eventos patológicos que resultam no recrutamento de neutrófilos, que por sua vez causam inflamação e necrose intestinal, além do aumento da secreção de fluido para o lúmen intestinal, resultando em diminuição da absorção, perda de proteína sérica e liberação de endotoxinas para a circulação, seguido de septicemia. As bactérias são fagocitadas por células de defesa, onde a salmonela tem a capacidade de sobreviver e se multiplicar (Hernandez et al., 2014).

A infecção por salmonella e subsequente desenvolvimento da doença clínica dependem de fatores ambientais, do agente e do hospedeiro. Fatores como idade, antibióticoterapia, mudança de dieta, transporte, entre outros episódios estressantes podem predispor a doença (Hernandez et al., 2014). Clinicamente são reconhecidas quatro síndromes clínicas de Salmonelose incluindo: (1) Doença assintomática com estado de portador latente ou ativo, (2) doença febril leve sem alterações significativas na consistência fecal, (3) enterocolite superaguda com diarreia e (4) septicemia. Os sinais clínicos podem variar, mas frequentemente é observado hipertermia, depressão, inapetência, cólica e refluxo gastroentérico. A diarreia pode ser leve e pastosa à abundante e profusa com a presença ou não de sangue. O comprometimento extra intestinal como uveíte, sinovite, osteomielite, pneumonia e meningite são consequências da bacteremia, comum em potros com menos de 2 meses de idade (Lester, 2001). Os achados hematológicos são inespecíficos e podem ser observados em outras enterites, como aumento do hematócrito pela hemoconcentração, leucopenia por neutropenia e linfopenia e hipoproteinemia como resultado da perda de proteínas decorrente do dano entérico (Hernandez et al., 2014)

$\mathrm{O}$ isolamento bacteriano a partir de fezes, através de meios de cultura convencionais como ágar sangue e ágar MacConkey ou seletivos como Salmonella-Shigella, é um método de diagnóstico "padrão ouro" e altamente sensível, entretanto, em baixas concentrações do organismo nas fezes ou pelo uso prévio de antibióticos, pode ocorrer culturas falso negativas (Hernandez et al., 2014). Além disso, a eliminação intermitente de salmonella é comum e, portanto, um mínimo de três a cinco culturas fecais consecutivas de 1 grama retiradas com 24 horas de intervalo é recomendado para aumentar a sensibilidade do teste (Slovis, 2011). Após isolamento bacteriano, as cepas podem ser identificadas de acordo com os sorovares por tipagem fenotípicas ou genética (Hernandes et al., 2014). A detecção do agente em amostras fecais pela técnica 
de PCR apresenta maior sensibilidade, quando comparada com a cultura e pode quantificar a carga bacteriana presente nas amostras fecais (Ward et al., 2005; Pusterla et al., 2010a).

Em potros com menos de 1 mês de idade, a hemocultura é recomendada, tendo em vista que potros jovens com salmonelose frequentemente desenvolvem bacteremia, entretanto, devido as dificuldades inerentes da técnica e a demora para a obtenção do resultado, ela é pouco empregada na rotina de diagnóstico (Lester, 2001). A lesão predominantemente observada na necropsia é a inflamação difusa fibrinosa ou hemorrágica do ceco e cólon. Os linfonodos mesentéricos estão aumentados e podem apresentar hemorragia e edema. (Hernandez et al., 2014). As amostras post mortem para isolamento bacteriano, devem incluir conteúdo cecal e colônico, linfonodos mesentéricos, fígado e baço, bem como quaisquer outros locais com lesões macroscópicas (Hernandez et al., 2014).

\subsection{Escherichia coli}

A Escherichia coli (E.coli) é uma bactéria Gram negativa descrita como a causa mais comum de septicemia em potros neonatos, mas, diferentemente de outras espécies, é um patógenos entérico primário incomum em potros (Zimmel, 2008; Kolk \& Kroeze, 2013). A doença entérica geralmente acomete potros com menos de 1 mês de vida e os sinais clínicos envolvem a presença de diarreia aquosa e profusa, com grave desidratação e desequilíbrio hidroeletrolítico, que contribuem para a alta mortalidade em neonatos. (Holland et al., 1996).

Por ser uma bactéria presente na microbiota entérica de potros e facilmente isolada a partir de amostras fecais, deve-se realizar a diferenciação de estirpes patogênicos através de PCR, pois os isolados geralmente identificados em culturas fecais não possuem fatores de virulência necessários para desenvolver a doença entérica (Zimmel, 2008). Entretanto, apesar da patogenicidade reconhecida da E. coli em humanos e outras espécies, os principais fatores de virulência associados a infecção entérica em potros permanecem desconhecidos. Apesar disso, estudos sugerem que as cepas de E.coli isolada de potros com diarreia podem expressar alguns fatores de virulência em comum com cepas que causam diarreia em outras espécies (Olivo et al., 2016).

\subsection{Clostridium difficile}

O Clostridium difficile (C. difficile) é um bacilo Gram positivo anaeróbico e formador de esporo, relatado como patógeno bacteriano associado a enterocolite em humanos e animais, acometendo tanto equinos adultos como potros (Baverud, 2004; Silva et al., 2012; Diab et al., 2013). No Brasil, são escassos os estudos de infecção por $C$. difficile em potros e estão restritos a dois relatos de caso e um estudo epidemiológico nos estados de Minas Gerais e São Paulo, respectivamente (Silva et al., 2012, Preis et al., 2012; Olivo et al., 2016). Ainda assim, estes relatórios apontam a possibilidade de uma incidência subestimada de diarreia causada por este agente em potros no Brasil.

A rota de transmissão, assim como a de outros agentes, ocorre pela via fecal-oral, sendo que a forma esporulada do agente pode permanecer no ambiente por até 4 anos (Baverud et al., 2004; Slovis, 2011). A patogênese da doença é atribuída a colonização e crescimento excessivo deste microorganismo com a produção subsequente de 2 principais toxinas que atuam sinergicamente: A Enterotoxina (toxina A- TcdA), com atividade citotóxica e alteração de permeabilidade intestinal e a Citotoxina (toxina B- TcdB), com atividade citotóxica até 100x maior que a toxina A. Além disso, alguns isolados produzem um fator de virulência adicional denominado toxina binária (Adenosine diphosphate ribosyltransferase- CDT), entretanto, sua relação com a doença não está bem estabelecida (Knoop et al., 1993; Weese, 2007; Arroyo et al., 2006). Assim como em humanos, o crescimento excessivo do $C$. difficile em potros e equinos adultos ocorre em decorrência da disbiose, caracterizada pelo desequilíbrio simbiótico da microbiota intestinal em detrimento ao aumento de bactérias patogênicas, podendo ser ocasionada pelo uso prévio de antibióticos (Wesse et al., 2000; Almeida et al., 2021). 
A prevalência de $C$. difficile em potros com diarreia varia entre 3 a 33\% (Weese et al., 2001; Frederick et al., 2009; Slovis et al., 2014; Olivo et al., 2016), sendo que esta variabilidade pode refletir as diferenças de sensibilidade e especificidade do teste diagnóstico, prevalência regional, idade do animal e fatores predisponentes. Estudos relatam a eliminação fecal de $C$. difficile em $29 \%$ dos potros saudáveis < 14 dias de idade e em $44 \%$ dos potros sem diarreia sob tratamento com antibiótico (Baverud et al., 2003).

A apresentação clínica em potros pode variar de enterite com leve desconforto abdominal a enterocolite fulminante com hemorragia e necrose do epitélio intestinal (Slovis, 2011). Os sinais clínicos podem se manifestar em potros logo após o nascimento, sendo observado depressão, diarreia aquosa com a presença ou não de sangue, cólica, presença de gases no intestino, desidratação e sepse seguida de morte (Diab et al., 2013). Além disso, os potros podem ser portadores assintomáticos da bactéria. Baverud e colaboradores (2004) relataram a eliminação do C. difficile em amostras fecais em 44\% dos potros assintomáticos sob tratamento com eritromicina e rifampicina e 15\% sob tratamento com sulfonamidas/trimetoprina e penicilina. Além disso, 28,5\% dos potros identificados como portadores assintomáticos tinham menos de 14 dias de vida. Do mesmo modo, Magdesian \& Leutenegger (2011) identificaram cepas de C. difficile em 36\% de éguas e seus potros, indicando que estes indivíduos podem abrigar o $C$. difficile subclinicamente e podem ser potenciais reservatórios para a colonização entre si.

De acordo com Silva e colaboradores (2014), não existe uma técnica "padrão ouro" para o diagnóstico de diarreia associada a infecção por $C$. difficile em potros. Em contrapartida, na medicina humana, o ensaio de citotoxicidade e a cultura toxigênica são técnicas consideradas "padrão ouro" no diagnóstico. A cultura bacteriana em meios de crescimento seletivo é uma técnica de difícil execução e deve ser sempre associada com a detecção de toxina, pois aproximadamente $25 \%$ dos isolados não expressam genes que codificam a produção de toxinas, e por sua vez, não são patogênicos (Delmée, 2001; Weese, 2020). Além disso, devido à baixa aerotolerância de bactérias anaeróbicas, a redução da taxa de recuperação de $C$. difficile de amostras fecais armazenadas aerobicamente podem gerar resultados falso negativos. Por este motivo, cultura bacteriana negativa associada a detecção de toxina positiva devem ser considerados verdadeiros positivos, pois as toxinas apresentam maior estabilidade em amostras armazenadas aerobicamente (Diab et al., 2013).

A detecção de toxinas em amostras fecais pode ser realizada pela observação do efeito citopático em linhagens celulares, entretanto, a necessidade da manutenção de cultivos celulares torna esta técnica onerosa e demorada. Em contrapartida, a deteç̧ão de toxinas por testes imunoenzimáticos comerciais (ELISA) são mais econômicos e de fácil execução, permitindo a obtenção de resultados mais imediatos, entretanto, podem apresentar menor sensibilidade e especificidade quando comparados com o ensaio de citotoxicidade (Slovis, 2011, Silva et al., 2014). Além disso, diferenciação de estirpes toxigênicos e não toxigênicos também pode ser realizada pela técnica de PCR, que detecta genes que codificam a produção de toxinas produzidas pelo $C$. difficile, tanto em amostras fecais, conteúdo intestinal e isolados bacterianos (Weese et al., 2000; Baverud; 2002).

No diagnóstico post-mortem, as lesões são caracterizadas por colite fibronecrotica com hemorragia e edema, e em potros com menos de 30 dias de vida são observadas com maior frequência no intestino delgado, e com menor frequência em cólon e céco. Em contrapartida, em potros com idade entre 1 à 12 meses, as lesões apresentaram distribuição aboral, comprometendo com maior frequência cólon e ceco e raramente o intestino delgado (Preis et al., 2012; Diab et al., 2013). O conteúdo intestinal é frequentemente hemorrágico, mas também pode se apresentar como conteúdo pastoso de coloração amarelada ou conteúdo liquido de coloração marrom esverdeada (Diab et al., 2013). 


\subsection{Clostridium perfringens}

O Clostridium perfringens (C. perfringens) é uma bactéria anaeróbica Gram positiva e formadora de esporos, amplamente disseminada no solo, presente na microbiota entérica de animais saudáveis e associado a enterocolite em humanos e animais (Slovis, 2011). A capacidade de produção de toxinas entre as cepas de C. perfringens é a base do sistema de classificação dos estirpes toxigênicos, que foi revisado recentemente e inclui 7 toxinotipos (A-G) com base na produção das toxinas tipificantes alpha (cpa), beta (cpb), épsilon (etx), iota (itx), enterotoxina (CPE) e a toxina semelhante a enterite B necrótica (NetB) (Rood et al., 2018). Além, disso, algumas cepas podem produzir fatores de virulência adicionais, classificados como toxinas não tipificantes, como a toxina $\beta 2$ (cpb2) (Gibert et al., 1997; Hazlett et al., 2011) e as toxinas formadoras de poros (NetF) (Gohari et al., 2015; 2016; 2020), que recentemente, foram identificadas em episódios de enterocolite em potros. A ação das toxinas envolve a ligação a um receptor de membrana plasmática de células alvo, seguida da ativação de vias intracelulares de efeitos citopáticos que levam a morte celular, resultando em dano intestinal (Uzal et al., 2010).

Os principais estirpes envolvidos em enterocolites em potros são o C. perfringens tipo A, produtor da toxina cpa, isolado tanto de animais saudáveis como animais doentes, e C. perfringens tipo C, produtor das toxinas cpa e cpb, raramente encontrado em fezes de animais saudáveis e associado a enterocolite neonatal em potros (Petit et al., 1999; Tillotson et al., 2002). O C. perfringens tipo A associado a produção da toxina CPE e a cpb2 (recentemente denominado C. perfringens tipo F) pode também ser encontrado em fezes de potros saudáveis, entretanto, a presença desses fatores de virulência geralmente é associado a episódios de diarreia (Tillotson et al., 2002; Rood et al., 2018).

A patogênese da doença está associada ao rompimento da resistência a colonização, ou seja, a alteração do ambiente simbiótico da microbiota entérica, que permite a colonização abundante e multiplicação do $C$. perfringens potencialmente patogênico, que pode ser desencadeada principalmente pela mudança na dieta, antibióticoterapia, estresse, hospitalização, infecção concomitante, imunidade e a presença de receptores intestinais para as toxinas de C. perfringens (Slovis, 2011).

A Transmissão de C. perfringens é fecal-oral ou ambiental, incluindo a contaminação pelo úbere da égua, sendo observada geralmente em potros com menos de 5 dias de idade (Tillostson et al., 2002, Zimmel, 2008; Slovis, 2011). Os sinais clínicos podem variar de diarreia sanguinolenta transitória à severa enterocolite com hemorragia aguda, cólica, peritonite, hipertermia, e desidratação. As complicações decorrentes da SIRS (síndrome da resposta inflamatória sistêmica) contribui para a rápida evolução da doença e consequentemente óbito. (Slovis, 2009). A doença induzida por $C$. perfringens tipo $C$ apresenta maior mortalidade (83\%) quando comparada ao tipo A (28\%) (Zimmel,2008). Em alguns casos de enterocolite associada a $C$. perfringens tipo $\mathrm{C}$, os potros podem desenvolver cólicas agudas sem diarreia, com rápida evolução e morte súbita (Diab et al.,2012).

O diagnóstico é baseado no isolamento do agente do conteúdo intestinal e na identificação de toxinas (Slovis, 2009). $\mathrm{O}$ isolamento do agente não associado a identificação de toxinas é considerado inapropriado, pois há possibilidade de isolamento do C. perfringens tipo A não toxigênico, já que o agente também é encontrado em indivíduos saudáveis (Slovis, 2009). A hemocultura é recomendada em potros neonatos, pois geralmente apresentam bacteremia por C. perfringens e raramente por $C$. difficile (Zimmel, 2008). Testes imunoenzimáticos através de kits comerciais de detecção de toxinas estão disponíveis e são utilizados no diagnóstico de infecção por C. perfringens. Além disso, a identificação das toxinas em amostras fecais ou conteúdo intestinal pode ser realizada através de protocolos de PCR estabelecidos para identificar os genes que codificam as toxinas e são amplamente utilizados na rotina de diagnóstico laboratorial (Baums et al., 2004). Na avaliação pós mortem, o intestino delgado e eventualmente do intestino grosso apresentam necrose e hemorragia difusa da mucosa intestinal com a presença de conteúdo intestinal hemorrágico (Diab et al., 2012). 


\subsection{Rhodococcus equi}

O Rhodococcus equi (R. equi) é uma bactéria cocobacilo, aeróbia, Gram positiva, intracelular facultativa, saprófita do solo, de ampla distribuição mundial e encontrada nas fezes de animais herbívoros (Hines, 2014). A infecção por $R$. equi ocorre nos primeiros dias de vida do potro até os 6 meses de idade, porém, com maior frequência entre 45 e 60 dias em virtude do estágio imunológico de declínio da imunidade passiva e início da imunidade ativa (McCracken et al., 2015). O tipo de solo, condições climáticas, ambiente empoeirado, manejo e densidade populacional são determinantes para a ocorrência da doença (Sprayberry, 2002). Além disso, considerando que algumas éguas são mais propensas a gerarem potros afetados, se sugere que fatores genéticos podem influenciar a suscetibilidade do hospedeiro, sendo modulado por fatores ambientais (Horin et al., 2010). A contaminação de potros ocorre pela inalação de partículas bacterianas, ou via oral, pela ingestão de solo ou forragem contaminada e coprofagia (Sprayberry, 2002).

O R. equi é o principal patógeno de doença respiratória em potros, entretanto, manifestações extrapulmonares podem ser observadas, sendo as manifestações entéricas as mais prevalentes (Reuss et al., 2009). Em um estudo epidemiológico realizado na região de Bagé-RS por Ribas et al. (2009) foi demonstrado que o R. equi apresentou uma prevalência de $17 \%$ em potros e uma taxa de letalidade de 50\%, entretanto, não foi descrita a presença de alterações extrapulmonares.

As manifestações entéricas são caracterizadas por colite ulcerativa e linfadenite mesentérica e podem estar presentes em até 50\% dos casos de pneumonia, sendo que em apenas 4\% dos casos não é observada doença respiratória prévia (Weese, 2008). Os sinais clínicos são caracterizados por diarreia, desidratação, cólica, perda de peso, hipertermia e leucocitose. Outras manifestações extrapulmonares incluem uveíte séptica, osteomielite, artrite e fisite séptica (Heidmann, 2006).

O diagnóstico clínico de R. equi é baseado em dados clinico epidemiológicos associados a exames complementares como radiografia, ultrassonografia, citologia, cultivo bacteriano em meios seletivos e amplificação da proteína associada a virulência (VapA) pela técnica de PCR a partir de lavado traqueobrônquico, para caracterização de cepas patogênicas (Giguère et al., 2011). Para manifestações extrapulmonares, o diagnóstico é baseado na cultura e amplificação da proteína VapA de amostras fecais (Giguère et al., 2011). Cepas de R. equi sem plasmídeos de virulência são incapazes de sobrevier e replicar em macrófagos, não sendo virulentas para potros (Spratberry, 2002; Hines et al., 2014). Testes sorológicos são realizados através das técnicas de imunodifusão em gel de agar, inibição de hemólise sinérgica, imunodifusão radial e Elisa, e indica a exposição ao agente ou presença de anticorpos maternos não sendo indicado como método de diagnóstico (Giguère et al., 2011).

$\mathrm{Na}$ avaliação post-mortem as lesões pulmonares são caracterizadas principalmente pela presença de nódulos multifocais com conteúdo purulento de coloração branco-amarelado, acompanhado por consolidação pulmonar crânio-ventral. As lesões entéricas são caracterizadas por linfadenite mesentérica e colônica, lesões ulcerativas e piogranulomatosas no intestino delgado, ceco e cólon, abscessos intra-abdominais e peritonite (Reus et al., 2009).

\subsection{Lawsonia intracellularis}

A Lawsonia intracellularis (L. intracellularis) é uma bactéria Gram-negativa, intracelular obrigatória, que reside dentro do citoplasma apical dos enterócitos de indivíduos infectados. A doença é difundida mundialmente em criações de suínos (Lawson \& Gebhart, 2000; Macedô et al., 2008) e nos últimos anos se tornou uma doença entérica emergente em potros.

A infecção por L. intracellularis associada a manifestação entérica é denominada Enteropatia Proliferativa Equina (EPE) e existem vários relatos na América do Norte (Schumacher et al., 2000; Bihr, 2003; Sampieri et al., 2006; Lavoie et al., 2000) Austrália (McClintock \& Collins, 2004) e Europa (Deprez et al., 2005; Wuersch et al., 2006). No Brasil, atualmente, formam reportados 3 casos de circulação de L. intracellularis em equinos. A primeira evidência de circulação do agente em equinos foi descrita por Guimarães-Ladeira et al. (2009) no estado de Minas Gerais, acometendo potros assintomáticos e com 
histórico de diarreia. Os outros dois relatos foram reportados na região sudeste e centro-oeste do Brasil, confirmando a presença da doença através dos sinais clínicos, PCR de amostras fecais, lesões patológicas e Imunohistoquímica (Guttmann et al., 2014; Gabardo et al., 2015).

A EPE pode se manifestar em potros de 3 à 11 meses de idade, com o pico de incidência clinica ocorrendo durante ou logo após o desmame (Lavoie et al., 2000; Barrelet, 2011), porém esta associação ainda não está bem estabelecida, sendo que outros fatores podem estar envolvidos no aparecimento da doença, como tempo de exposição e quantidade de bactéria a que o potro foi exposto, além do "status" imune e endoparasitismo. Do mesmo modo, é descrito que a EPE é mais frequente entre outono e início do inverno, entretanto são necessário mais estudos para afirmar que a EPE está associada a prevalência estacional, faixa etária e/ou pratica de manejo (Macedô et al., 2008).

A rota de contaminação de equinos, assim como em outras espécies, é fecal-oral, sendo que animais domésticos e selvagens podem atuar como reservatórios e disseminadores da doença (Lavoie et al., 2000; Lawson \& Gebhart, 2000). Os animais portadores podem eliminar a $L$. intracellularis no ambiente por até 27 dias e a bactéria pode se manter em condições ambientais por até 2 semanas a temperatura de $5-15^{\circ} \mathrm{C}$ (Collins et al., 2000; Pusterla et al., 2012).

A L. intracellularis coloniza o epitélio do intestino delgado, levando espessamento edematoso da mucosa, geralmente observado em íleo, seguido do envolvimento do cólon (Smith \& Lawson, 2001). É proposto que a L. intracellularis afeta os enterócitos mitoticamente ativos das criptas intestinais, onde se torna dependente da mitose das células hospedeiras para sua propagação, que por sua vez, resulta na proliferação e hiperplasia das células da cripta, levando a superpopulação de células epiteliais imaturas e sem microvilosidades, resultando em diarreia por má absorção e consequentemente hipoproteinemia. (Smith \& Lawson, 2001; Pusterla \& Gebhart 2009).

A doença cursa com sinais clínicos como letargia, febre, edema periférico, cólica, diarreia e espessamento da parede do intestino delgado (Pusterla \& Gebhart, 2013). A perda de peso crônica pode ocorrer e é uma das razões pelas quais a doença pode ter um impacto devastador em propriedades destinadas a venda de potros. Embora a diarreia seja comumente observada em potros afetados e possa variar de fezes pastosa a aquosa, alguns potros podem não apresentar anormalidades nas fezes (Pusterla \& Gebhart, 2013). Os achados clínico patológicos mais comuns são hipoproteinemia, hipoalbuminemia, leucocitose e hiperfibrinogenemia (Frazer, 2008). Estudos epidemiológicos indicam que 10 a 65\% dos cavalos adultos assintomáticos são soropositivos. Além disso, semelhante aos suínos, a doença pode se apresentar de forma subclínica em potros, sendo observada uma diminuição autolimitada e transitória da concentração de proteína sérica total associada a diminuição de ganho de peso diário em comparação com potros saudáveis (Pusterla et al., 2010b).

O diagnóstico ante mortem é baseado na detecção do agente em amostras fecais por meio de PCR e/ ou sorologia por Imunofluorescência indireta (IFI) ou Imunoperoxidase em monocamada de células (IPMA) (Pusterla et al., 2010c; Macedô et al., 2008). A análise por PCR de amostras fecais é um teste específico mas de sensibilidade moderada devido a possibilidade de eliminação intermitente do organismo ou da presença de inibidores fecais (Frazer, 2008; Barrelet, 2011). Além disso, resultados falso negativos podem ser obtidos após o início do tratamento antimicrobiano (Barrelet, 2011). Do mesmo modo, resultados negativos de sorologia em equinos com sinais clínicos de EPE podem indicar que a doença esteja no estágio inicial, quando a resposta imune humoral ainda não é suficiente para ser detectada em exames sorológicos (Frazer, 2008). A taxa de exposição a $L$. intracellularis é maior que a taxa de doença clínica, por este motivo, é aconselhável realização de testes sorológicos em animais que tenham contato com indivíduos com EPE, entretanto, o PCR das fezes de potros assintomáticos não é aconselhável para o monitoramento, pois a taxa de eliminação bacteriana nas fezes é rara (Pusterla et al., 2010c). Em estudos clínicos, potros com titulação de IPMA $\geq 60$ eram considerados soropositivos, e títulos mais altos se correlacionavam com doença grave (Pusterla et al., 2010c). 
$\mathrm{Na}$ necropsia, as lesões macroscópicas frequentemente observadas são caracterizadas pelo espessamento difuso da mucosa do intestino delgado e redução do lúmen intestinal, atribuído a hiperplasia das criptas e edema transmural. Na análise histológica é observado o marcante encurtamento das vilosidades intestinais, hiperplasia dos enterócitos das criptas e enterócitos colunares imaturos (Wuersch et al., 2006; Gabardo et al., 2015). O diagnóstico definitivo post-mortem pode ser realizado durante o exame histopatológico pela detecção da bactéria na parte apical do citoplasma do enterócito por coloração de prata, entretanto, está coloração não é específica para L. intracellularis (Wuersch et al., 2006). A utilização de Imunohistoquímica (IHQ) é considerado "padrão ouro" para detecção de L. intracellularis através da marcação de antígeno no ápice citoplasmático dos enterócitos e macrófagos em amostras de tecido intestinal (Schumacher et al., 2000). Além disso, os tecidos intestinais também podem ser testados quanto a presença do agente por meio de PCR, utilizando porções da mucosa ou conteúdo intestinal (Wilson \& Gebhart, 2008).

\subsection{Rotavírus Equino}

O Rotavírus Equino (RVE) é um vírus pertencente à família Reoviridae, RNA fita dupla não envelopado e classificado no Grupo A, de acordo com características antigênicas (Dwyer, 1993). O seu genoma consiste em 11 segmentos gênicos que codificam seis proteínas estruturais (VP1-4, VP6-7) e seis proteínas não estruturais (NSP1-6). Os genes de duas proteínas do capsídeo externo VP7 (tipo G) e VP4 (tipo P) são usados para genotipagem. Os genes G3P[12] e G14P[12] estão entre os mais prevalentes em potros, enquanto que os outros isolados menos descritos em equinos, são casos de transmissão cruzada entre espécies (Bailey, 2013). O RVE possui distribuição mundial e é a principal causa de gastroenterite viral aguda em potros jovens, sendo identificado em 20 a 77\% dos casos clínicos de diarreia (Frederick et al. 2009; Bayle et al., 2013; Slovis et al., 2014; Magdesian et al., 2014).

A transmissão do RVE é feita pela via fecal-oral através de fezes e fômites contaminados, onde o vírus pode permanecer viável por até 9 meses em temperatura ambiente (Bayle et al., 2013; Magdesian et al., 2014). O período de incubação é curto, de 12 a 24 horas, permitindo o desenvolvimento de surtos, com vários potros podendo desenvolver a doença em um curto período de tempo (Bailey et., 2013; Magdesian et al.,2014). Em potros, não é descrito a dose mínima infectante e os títulos virais eliminados nas fezes, contudo, estudos em suínos demonstram que a infecção por rotavírus pode ocorrer com 90 partículas virais, sendo que um indivíduo infectado pode eliminar até $10^{10}$ partículas de rotavírus por grama de fezes (Payment \& Morin, 1990).

Dwyer em 1993 e Bora e colaboradores em 2011 demonstraram a eliminação do Rotavírus em amostras fecais de leitoas assintomáticas durante o período pré e pós parto, sendo assim, fonte de contaminação para o neonato. Em equinos, não é descrita a participação da égua na transmissão de RVE ao neonato, embora algumas éguas com potros sintomáticos possam apresentar soroconversão e eventualmente eliminar baixas concentrações virais nas fezes de forma transitória (Higgins, 1998). Entretanto, essa eliminação não é significativa quando comparada com potros, onde a disseminação viral nas fezes pode ocorrer durante a fase clínica da doença, com duração de 1-12 dias e em infecções subclínicas (Higgins, 1988; Dwyer, 1993).

A gravidade da infecção por RVE depende da idade e "status" imunológico do potro, assim como da virulência e quantidade de inoculo viral, acometendo principalmente potros com 3 meses de idade e exibindo maior morbidade e mortalidade em neonatos, devido a capacidade limitada de auto correção de desequilíbrio hidroeletrolítico que acompanha a diarreia (Magdesian et al., 2014). Na maioria dos casos, a diarreia é auto limitante, contudo, os mecanismos imunossupressores do RV podem promover a colonização do intestino por outros agentes patogênicos e consequentemente, aumentar a gravidade da doença (Magdesian, 2006; Bayle et al., 2013).

A patogênese da rotavirose é caracterizada principalmente por má absorção devido a infecção dos enterócitos presentes no ápice das vilosidades do intestino delgado (Bayle, 2013). O vírus se replica no citoplasma dos enterócitos, 
resultando em lise celular e atrofia das vilosidades e consequentemente ausência de lactase, que por sua vez leva a intolerância a lactose transitória. A permanência deste açúcar no lúmen intestinal resulta na formação de um conteúdo hiperosmótico, aumentando a secreção intraluminal. A diminuição da capacidade absortiva e o aumento da secreção intraluminal caracteriza a diarreia aguda (Bayle, 2013; Magdesian et al., 2014). Além disso, o RVE produz uma enterotoxina viral, denominada NSP4, que atua em diversos mecanismos da patogênese da rotavirose em potros (Beua et al., 2007; Halaihel et al., 2000). As células da cripta continuam a replicação, diferenciação e substituição dos enterócitos comprometidos, caracterizando uma doença autolimitante (Magdesian et al., 2014).

Atualmente, a prevenção da diarreia por RVE é realizada pela administração de vacinas inativadas em éguas no terço final da gestação, com intuito de induzir a imunidade colostral e lactogênica (Bailey et al., 2013). Apesar disso, o rotavírus ainda é uma das principais causas de diarreia em potros, sugerindo que as vacinas utilizadas atualmente não induzem imunidade suficiente contra o vírus. Estudos de infecção experimental e a campo mostraram que potros podem adquirir a doença mesmo apresentando níveis substanciais de anticorpos circulantes, porém, com redução da gravidade dos sinais clínicos e de eliminação do vírus nas fezes (Imagawa et al., 2005). Estudos em terneiros demonstram que o anticorpo colostral tem efeito protetor limitado contra a diarreia rotaviral, e que a proteção máxima é alcançada pela presença continua de anticorpos neutralizantes no leite materno, sugerindo que a máxima eficiência da vacinação de vacas gestantes depende da indução da imunidade lactogênica (Parreno et al., 2010). Até o momento, não está claro o efeito das vacinais comerciais na indução da imunidade lactogênica em éguas, seguida da modulação da resposta imune local em seus potros. As vacinas contra Rotavírus equino licenciadas no mercado mundial são desenvolvidas no EUA, Japão e Argentina, contudo, a indisponibilidade de comercialização no mercado brasileiro e a dificuldade em importação são problemas frequentemente relatados por médicos veterinários no Brasil. Por este motivo, o estudo epidemiológico e o sequenciamento genético das cepas de RV associadas a diarreia em potros são importantes para o futuro desenvolvimento de uma vacina brasileira capaz de induzir imunidade aos potros através de anticorpos colostrais.

O isolamento e cultivo celular do RVE é complexo e de difícil execução, por isso, a demonstração direta de antígeno viral em amostras biológicas são os métodos de diagnóstico empregados na rotina laboratorial. O diagnóstico de rotavirose pode ser realizado por microscopia eletrônica (ME) através da visualização de partículas virais em amostras fecais, porém, está técnica apresenta baixa sensibilidade quando a concentração de partículas virais por gramas de fezes é baixa, não sendo empregada no diagnóstico de rotina laboratorial (Dwyer et al., 1993). Os ensaios imunoenzimáticos (ELISA) apresentam boa sensibilidade quando comparados a ME e são baseados em uma proteína do capsídeo intermediário, a mais abundante em partículas virais e altamente conservada entre os rotavírus do grupo A de várias espécies. Por esse motivo, os ensaios comerciais baseados em técnicas de aglutinação em látex e imunocromatografia desenvolvidos para a detecção de antígeno viral em humanos, bovinos e suínos podem ser empregados no diagnóstico em equinos, sendo úteis para veterinários no campo (Nemoto et al., 2010, Bailey et al., 2013). Atualmente, os métodos de diagnóstico molecular como ensaios de reação em cadeia da polimerase (RT-PCR) utilizando primers projetados a partir de genes de RVE apresentam alta sensibilidade e especificidade, sendo adequados para genotipagem de RVE e amplamente utilizados para deteç̧ão do agente, tornando-se a técnica "padrão ouro" para o diagnóstico laboratorial (Magdesian et al., 2014; Vlasova et al., 2020).

\subsection{Coronavírus Equino}

O Coronavírus Equino (CoVE) é um vírus RNA fita simples, envelopado, pertencente à família Coronaviridade e classificado dentro do gênero Betacoronavírus, causador de doenças entéricas e respiratórias em humanos e animais (Magdesian et al., 2014). 
O CoVE pode atuar como patógeno primário em potros jovens e imunocomprometidos ou atuar como facilitador para infecções entéricas por patógenos oportunistas (Zimmel, 2008). Em um levantamento epidemiológico realizado no estado do Kentucky- EUA, potros sem diarreia e com diarreia foram infectados igualmente com coronavírus, sugerindo a alta circulação do vírus nessa população e a baixa patogenicidade do agente em potros. Entretanto, quando analisado as coinfecções, o coronavírus foi significativamente associado com a doença em potros, indicando que a pré existência do coronavírus facilita infecções secundárias por enteropatógenos oportunistas, pela diminuição da resposta imunológica local, como relatado em outras espécies (Brockmeier et al., 2008; Slovis et al.,2014). Fatores do hospedeiro como a ausência de locais de ligação ao receptor especifico ou a presença de anticorpos colostrais podem ser razões hipotéticas para a presença de potros assintomáticos infectados com CoVE (Pusterla et al., 2016).

A rota de transmissão se dá pela via fecal-oral e menos comum pela via respiratória (Magdesian et al., 2014). As infecções por CoVE são geralmente auto limitantes e os sinais clínicos são inespecíficos, caracterizados por prostração, hipertermia, diarreia, desidratação, podendo durar de 1 a 12 dias (Meirelles et al., 2008; Magdesian et al., 2014). No Sul do Brasil, estudos epidemiológicos indicam uma taxa de morbidade superior a 58\% entre potros com 30 a 90 dias de vida, período de queda da imunidade passiva e estabelecimento da imunidade ativa (Meirelles et al., 2008). A presença de indivíduos doentes ou portadores assintomáticos eliminando o vírus no ambiente e a prática de coprofagia são fatores de risco propostos para a infecção de potros imunocomprometidos (Meirelles et al., 2008).

O CoVE invade os enterócitos e se replica no citoplasma celular, causando dano as vilosidades da mucosa intestinal e consequentemente a diminuição da produção de enzimas intestinais, o que resulta na perda da capacidade absortiva e consequentemente, diarreia por má absorção (Magdesian et al.,2014).

Assim como o RV, o cultivo do CoVE é de difícil execução, e os métodos de diagnóstico baseados na demonstração direta de antígeno viral ou RNA viral em amostras biológicas são amplamente empregados (Pusterla et al., 2017). A ME pode ser utilizada para identificar partículas semelhantes a coronavírus em amostras fecais, porém, apresenta baixa sensibilidade quando as concentrações virais estiverem baixas (Magdesian et al., 2014). O teste de ELISA de captura fecal para antígeno pode ser utilizado para detectar o agente em amostras fecais, no entanto, o RT-PCR de amostras fecais apresenta maior sensibilidade e especificidade, sendo utilizado com maior frequência na rotina de diagnóstico laboratorial (Magdesian et al., 2014). Em casos de necropsia, amostras de conteúdo intestinal podem ser testadas por PCR e amostras de tecido intestinal fixadas em formalina podem ser testadas por Imunohistoquímica (Giannitti et al., 2015).

\subsection{Helmintos}

A manutenção de altas cargas parasitárias e a suscetibilidade a doença clínica associada ao parasitismo em potros são fatores negativos para o sucesso do manejo em sistemas de criação (Fabiani \& Nielsen, 2016). Potros com baixa infestação parasitária pode apresentar retardo no crescimento e desenvolvimento, sem manifestações clínicas mais significativas, entretanto, as altas infestações parasitárias podem estar associadas a episódios de diarreia e ao aumento da predisposição a infecções bacterinas e virais, como é descrito por Reinemeyer em 2008.

Strongyloides são pequenos nematódeos que parasitam o intestino delgado de várias espécies de animais domésticos (Lucena et al., 2012). Em equinos, o S. westeri tem sido associado a diarreia em potros jovens, podendo ser transmitido de forma passiva, através da pastagem ou aleitamento, ou ativa, quando ocorre penetração pela pele integra (Lucena et al., 2012). A infecção em potros ocorre geralmente entre o $9^{\circ}$ e $13^{\circ}$ dia, causando diarreia por até dez semanas (Bowman, 2010). A realização de protocolos sanitários através da administração de vermífugos periodicamente nas éguas progenitoras ajuda a reduzir a incidência desta doença (Zimmel, 2008). O diagnóstico de infecção por S. westeri é baseado na observação de ovos 
embrionados nas fezes frescas de potros pelo método de flutuação (Lucena et al., 2012). É descrito que infestações com mais de 2.000 ovos por grama de fezes são necessárias para o desenvolvimento da diarreia (Magdesian, 2006).

Os pequenos estrôngylos ou ciatostomíneos compreendem a classe de parasitas mais abundantes no intestino grosso de equinos, representando de 75 a 100\% dos ovos eliminados nas fezes de equinos naturalmente infectados. A manifestação clínica é consequência da emergência simultânea de um grande número de larvas encistadas em hipobiose na mucosa cecal e colônica. As larvas de ciatostomíneos incistadas no lúmen intestinal causam diarreia aquosa associada à inflamação grave da mucosa (Martins et al., 2005, Bowman, 2010). Na fase aguda os sinais clínicos são caracterizados por diarreia profusa, podendo ser de aspecto sanguinolento, com presença de desidratação e hipoproteinemia (Nielsen, 2017). O diagnóstico é realizado através da contagem de ovos por grama de fezes (OPG) associado a cultura larval para diferenciação entre pequenos e grandes Strongylus. Os achados macroscópicos incluem a presença de nódulos formados por larvas encistadas na mucosa do ceco e cólon associado a edema difuso e congestão da mucosa intestinal (Uzal \& Diab et al., 2015)

\section{Considerações Finais}

Os processos de diarreia em potros são multifatoriais e quando associados a agentes infecciosos podem envolver a ação de virus, bactérias e parasitas. Além disso, a composição da microbiota entérica comensal por agentes com potencial patogênico, torna o diagnóstico das enterocolites infecciosas um desafio. Nos últimos anos, os ensaios moleculares se tornaram uma importante ferramenta tecnológica e permitiram o aumento da capacidade de diagnóstico. Ainda assim, a avaliação do contexto clínico do indivíduo é indispensável para a interpretação do diagnóstico final.

Estudos epidemiológicos sobre a incidência de enterocolites em potros no Brasil são escassos. A realização de estudos que demonstrem os índices de infecção por enteropatógenos associados a diarreia em potros, assim como o sequenciamento das cepas isoladas em diferentes regiões são estudos que poderão auxiliar na padronização de plataformas de diagnóstico molecular de detecção múltipla (PCR multiplex) para identificação simultânea dos principais agentes etiológicos. Além disso, estudos de caracterização molecular de cepas circulantes podem permitir o desenvolvimento de vacinas direcionadas tanto à indução da imunidade passiva através de anticorpos colostrais, quanto à indução de imunidade celular em potros.

\section{Referências}

Almeida, J. M., Nader, R. G. M. \& Mallet, A. C. T. (2021) T. Intestinal microbiota in the first thousand days of life and its relation to dysbiosis. Research, Society and Development, 10(2), e35910212687.

Arroyo, L. G., Stampfli, H. R. \& Weese, J. S. (2006) Potential role of Clostridium difficile as a cause of duodenitis-proximal jejunitis in horses. Journal of Medical Microbiology, 55(5), 605-608.

Bailey, K. E., Gilkerson, J. R. \& Browning, G. F. (2013) Equine rotaviruses- Current understanding and continuing challenges. Veterinary Microbiology, 167(1-2), 135-144.

Barrelet, A. (2011). How to diagnose: Lawsonia. Proceedings of the 50th British Equine Veterinary Association Congress - Liverpool, United Kingdom.

Baums, C. G., Schotte, U., Amtsberg, G. \& Goethe, R. (2004) Diagnostic multiplex PCR for toxin genotyping of Clostridium perfringens isolates. Veterinary Microbiology, 100(1-2) 11-16.

Baverud, V. (2002) Clostridium difficile infections in animals with special reference to the horse. A review. Veterinary Quarterly, 24(4), 203-219.

Baverud, V., Gustafsson, A., Franklin, A., Aspán, A. \& Gunnarsson, A. (2003) Clostridium difficile: prevalence in horses and environment, and antimicrobial susceptibility. Equine Veterinary Journal, 35(5), 465-471.

Baverud, V. (2004) Clostridium difficile diarrhea: infection control in horses. Veterinary Clinics: Equine Practice, 20(3), 615-630.

Beau, I., Cotte-Laffitte, J., Géniteau-Legendre, M., Estes, M. K. \& Servin, A. L. (2007) An NSP4-dependant mechanism by which rotavirus impairs lactase enzymatic activity in brush border of human enterocyte-like Caco-2 cells. Cellular Microbiology, 9(9), 2254-2266.

Bihr, T. P (2003). Protein-losing enteropathy caused by Lawsonia intracellularis in a weanling foal. The Canadian Veterinary Journal, 44(1), 65. 
Bora, D. P., Barman, N. N., Bhattacharyya, D. K. \& Dutta, L. J. (2011) Faecal excretion of rotavirus by naturally infected pregnant sows in organized pig farms-a potent source of infection to newborns. Indian Journal of Animal Sciences, 81(6), 575.

Bowman, D. D. G. (2010) Parasitologia veterinária.. Saunders.

Brockmeier, S. L., Loving, C. L., Nicholson, T. L. \& Palmer, M. V. (2008) Coinfection of pigs with porcine respiratory coronavirus and Bordetella bronchiseptica. Veterinary Microbiology, 128(2008), 36-47.

Cohen, N. D. (1994) Causes of and farm management factors associated with disease and death in foals. Journal of the American Veterinary Medical Association, 204(10), 1644-1651.

Collins, A., Love, R. J., Pozo, J., Smith, S. H. \& McOrist, S. (2000) Studies on the ex vivo survival of Lawsonia intracellularis. Journal of Swine Health and Production, 8(5), 211-215.

Delmée, M. (2001) Laboratory diagnosis of Clostridium difficile disease. Clinical Microbiology and Infection, 7(8), 411-416.

Deprez, P., Chiers, K., Gebhart, C. J., Ducatelle, R., Lefère, L., Vanschandevijl, K. \& Loon, G. V. (2005) Lawsonia intracellularis infection in a 12-monthold colt in Belgium. The Veterinary Record, 157(24), 774.

Diab, S. S., Kinde, H., Moore, J., Shahriar, M. F., Odani, J., Anthenill, L., Songer, G. \& Uzal, F. A. (2012) Pathology of Clostridium perfringens type C enterotoxemia in horses. Veterinary Pathology, 49(2), 255-263.

Diab, S. S., Songer, G., \& Uzal, F. A. (2013) Clostridium difficile infection in horses: a review. Veterinary Microbiology, 167(1-2), 42-49.

Dwyer, R. M. (1993) Rotaviral diarrhea. Veterinary Clinics of North America: Equine Practice, 9(2), 311-319

Fabiani, J. V. \& Nielsen, L. M. K. (2016) Dynamics of Parascaris and Strongylus spp. parasites in untreated juvenile horses. Veterinary Parasitology, 230, 6266.

Frazer, M. L. (2008) Lawsonia intracellularis infection in horses: 2005-2007. Journal of Veterinary Internal Medicine, 22(5), 1243-1248.

Frederick, J., Giguère, S. \& Sanchez, L. C. (2009). Infectious agents detected in the feces of diarrheic foals: a retrospective study of 233 cases (20032008). Journal of Veterinary Internal Medicine, 23(6), 1254-1260.

Gabardo, M. P., Sato, J. P. H., Resende, T. P. \& Guedes, R. M. C. (2015). Equine proliferative enteropathy on a Brazilian farm. Pesquisa Veterinária Brasileira, 35(5), 443-447.

Giannitti, F., Diab, S., Mete, A., Stanton, J. B., Fielding, L., Crossley, B., Sverlow, K., Fish, S., Mapes, S., Scott, L. \& Pusterla, N. (2015) Necrotizing enteritis and hyperammonemic encephalopathy associated with equine coronavirus infection in equids. Veterinary Pathology, 52(6), 1148-1156.

Gibert, M., Jolivet-Renaud, C. \& Popoff, M. R. (1997) Beta2 toxin, a novel toxin produced by Clostridium perfringens. Gene, 203(1), 65-73.

Giguère, S., Cohen, N. D., Chaffin, M. K., Slovis, N. M., Hondalus, M. K., Hines, S. A. \& Prescott, J. F. (2011). Diagnosis, Treatment, Control, and Prevention of Infections Caused by Rhodococcus equi in Foals. Journal of Veterinary Internal Medicine, 25(6), 1209-1220.

Guimarães-Ladeira, C. V., Palhares, M. S., Oliveira, J. S. V., Ramirez, M. A. \& Guedes, R. M. C. (2009) Faecal shedding and serological cross-sectional study of Lawsonia intracellularis in horses in the state of Minas Gerais, Brazil. Equine Veterinary Journal, 41(6), 593-596.

Gohari, M. I., Parreira, V. R., Nowell, V. J., Nicholson, V. M., Oliphant, K. \& Prescott, J. F. (2015) A novel pore-forming toxin in type A Clostridium perfringens is associated with both fatal canine hemorrhagic gastroenteritis and fatal foal necrotizing enterocolitis. PloS one, 10(4), e0122684.

Gohari, M. I., Parreira, V. R., Timoney, J. F., Fallon, L., Slovis, N. \& Prescott, J. F. (2016) NetF-positive Clostridium perfringens in neonatal foal necrotising enteritis in Kentucky. Veterinary Record, 178(9), 216-216.

Gohari, M. I., Unterer, S., Whitehead, A. E. \& Prescott, J. F. (2020) NetF-producing Clostridium perfringens and its associated diseases in dogs and foals. Journal of Veterinary Diagnostic Investigation, 32(2), 230-238.

Gray, J. T. \& Fedorka-Cray, P. J. (2001) Survival and infectivity of Salmonella choleraesuis in swine feces. Journal of Food Protection, 64(7), 945-949.

Guttmann, P. M., Viscardi, V., Barroso, D. A. \& Guedes, R. M. C. (2014) Equine Proliferative Enteropathy Caused by Lawsonia intracellularis in a Foal in Brazil. Journal of Equine Veterinary Science, 34(5), 701-703.

Halaihel, N., Liévin, V., Alvarado, F. \& Vasseur, M. (2000) Rotavirus infection impairs intestinal brush-border membrane Na+-solute cotransport activities in young rabbits. American Journal Physiology- Gastrointestinal and Liver Physiology, 279(3), G587-G596.

Harris, R., Sankar, K., Small, J. A., Suepaul, R., Stewart-Johnson, A. \& Adesiyun, A. (2012) Prevalence and characteristics of enteric pathogens detected in diarrhoeic and non-diarrhoeic foals in Trinidad. Veterinary Medicine International, 2012.

Hazlett, M. J., Kircanski, J., Slavic, D. \& Prescott, J. F. (2011) Beta 2 toxigenic Clostridium perfringens type A colitis in a three-day-old foal. Journal of Veterinary Diagnostic Investigation, 23(2), 373-376.

Heidmann, P., Madigan, J.E. \& Watson, J.L. (2006). Rhodococcus equi pneumonia: clinical findings, diagnosis, treatment and prevention. Clinical Techniques in Equine Practice, 5(3), 203-210.

Higgins, W. P., Gillespie, J. H., Schiff, E. I., Pennow, N. N., Tanneberger, M. J. (1987). Infectivity and immunity studies in foals with cell culturepropagated equine rotaviruses. In: Equine Infectious Diseases V: Proceedings of the Fifth International Conference, Lexington, Kentucky, 241-247. 
Hines, M. T. (2014) Rhodococcus equi. In: Sellon, D.C., Long, M. (2a ed.) Equine Infectious Diseases (pp. 287- 302). Missouri: Elsevier Health Sciences.

Hernandez, J. A., Long, M. T., Traub-Dargats, J. L. \& Besser, T. E. (2014) Salmonellosis. In: Sellon, D.C.; Long, M. (2ed.) Equine Infectious Diseases (pp. 321-333) Missouri : Elsevier Health Sciences.

Holland, R. E., Schimidt, A., Sriranganathan, N., Grimes, S. D., Wilson, R. A., Brown, C. M. \& Walker, R. D. (1996). Caracterization of Escherichia coli isolated from foals. Veterinary Microbiology, 48, 243-255.

Horin, P., Sabakova, K., Futas, J., Vychodilova, L. \& Necesankova, M. (2010). Immunity-related gene single nucleotide polymorphisms associated with Rhodococcus equi infection in foals. International Journal of Immunogenetics, 37(2), 67-71.

Imagawa, H., Kato, T., Tsunemitsu, H., Tanaka, H., Sato, S., \& Higuchi, t. (2005) Field study of inactivated equine rotavirus vaccine. Journal of Equine Science, 16(2), 35-44, 2005.

Knoop, F. C., Owens, M. \& Crocker, C. (1993) Clostridium difficile: clinical disease and diagnosis. Clinical Microbiology Reviews, 6(3), 251-265.

Kolk J. H. V. \& Kroeze, E. J. B. V. (2013). Infection disease of the horse. London: Manson.

Lavoie, J. P., Drolet, R., Parsons, D., Leguillette, R., Sauvageau, R., Shapiro, J., Houle, L., Hallé, G. \& Gebhart, C. J. (2000) Equine proliferative enteropathy: a cause of weight loss, colic, diarrhoea and hypoproteinaemia in foals on three breeding farms in Canada. Equine Veterinary Journal, 32(5), 418-425.

Lawson, G. H. K. \& Gebhart, C. J. (2000) Proliferative enteropathy. Journal of Comparative Pathology, 122(2-3), 77-100.

Lester, G. D. (2001) Infectious diarrhea in foals. In: Proceedings of the Annual Convention of the AAEP. 41, 468-471.

Lucena, R. B. Fighera, R. A. \& Barros, C. S. L. (2012). Foal mortality associated with Strongyloides westeri parasitism. Pesquisa Veterinária Brasileira, 32(5), 401-404

Macêdo, N. R. Al-Ghamdi, G., Gebhart, C. J. \& Guedes, R. M. C. (2008) Enteropatia proliferativa em equinos. Ciência Rural, 38(3), 889-897.

Magdesian, K. G. (2006) Gastrointestinal Disease. In: Paradis, M. R. Equine Neonatal Medicine- A Case Based Approach (pp. 191- 229). Philidelphia: Saunders.

Magdesian, K. G. \& Leutenegger, C. M. (2011) Real-time PCR and typing of Clostridium difficile isolates colonizing mare-foal pairs. The Veterinary Journal, 190(1), 119-123.

Magdesian, K. G., Dwyer, R. M. \& Arguedas, M. G. (2014) Viral Diarrhea. In: Sellon, D.C. \& Long, M. (2Ed.), Equine Infectious Diseases (pp. 198-203). Missouri: Elsevier Health Sciences.

Mallicote, M., House, A. M. \& Sanchez, L. C. (2012) A review of foal diarrhea from birth to weaning. Equine Veterinary Education, 24(4), $206-214$.

Martins, I.V. F., Pereira, M. J. S., Grisi, L., \& Scott, F. B. (2005). Seasonal abundance of equine strongyles (Nematoda: Strongylidae) in the State of Rio de Janeiro, Brazil. Arquivo Brasileiro de Medicina Veterinária e Zootecnia, 57(1), 43-47.

McClintock, S. A. \& Collins, A. M. (2004) Lawsonia intracellularis proliferative enteropathy in a weanling foal in Australia. Australian Veterinary Journal, 82(12), 750-752.

McCracken, J. L. (2015) Screening for Rhodococcus equi Pneumonia. In: Sprayberry, K.A; Robinson, N.E (7ed.), Robinson's Current Therapy in Equine Medicine (pp. 79-131). Missouri: Saunders.

Nemoto, M., Tsunemitsu, H., Murase, H., Nambo, Y., Sato, S., Orita, Y., Imagawa, H., Bannai, H., Tsujimura, K., Yamanaka, T., Matsumura, T. \& Kondo, T. (2012). Antibody response in vaccinated pregnant mares to recent G3BP [12] and G14P [12] equine rotaviruses. Acta Veterinaria Scandinavica, 54(1), 1-5.

Nielsen, M. K. (2017). Internal Parasite Screening and Control. In: Sprayberry, K.A \& Robinson, N.E. (7ed.), Robinson's current Therapy in equine medicine (pp. 336-340). Missouri: Saunders.

Olivo, G., Lucas, T. M., Borges, A. S., Silva, R. O. S., Lobato, F. C. F., Siqueira, A. K., Leite, D. S., Brandão, P. E., Gregori, F., Oliveira-Filho, J. P., Takai, S. \& Ribeiro, M. G. (2016). Enteric Pathogens and Coinfections in Foals with and without Diarrhea. BioMed research international, 2016.

Parreño, V., Marcoppido, G., Vega, C., Garaicoechea, L., Rodriguez, D., Saif, L., \& Fernández, F. (2010). Milk supplemented with immune colostrum: Protection against rotavirus diarrhea and modulatory effect on the systemic and mucosal antibody responses in calves experimentally challenged with bovine rotavirus. Veterinary immunology and immunopathology, 136(1-2), 12-27.

Payment, P. \& Morin, E. (1990) Minimal infective dose of the OSU strain of porcine rotavirus. Archives of Virology, 112(3-4), 277-282.

Pereira, A. S., Shitsuka, D. M., Parreira, F.J. \& Shitsuka, R. (2018). Metodologia da pesquisa científica, $1^{\circ}$ Edição UBA/NTE/UFSM, Universidade Federal de Santa Maria.

Petit, L., Gibert, M., \& Popoff, M. R. (1999). Clostridium perfringens: toxinotype and genotype. Trends in microbiology, 7(3), 104-110.

Preis, I. S., Silva, R. O., Pires, P. S., Lobato, F. C., Palhares, M. S., Maranhão, R. P., \& Ecco, R. (2012). Enteritis associated with Clostridium difficile and opportunistic candidiasis in a foal. Brazilian Journal of Veterinary Pathology, 5(1), 7-11.

Pusterla, N; Gebhart, C. (2009) Enteropatia proliferativa equina causada por Lawsonia intracellularis. Educação Veterinária Equina, 21(8), 415-419.

Pusterla, N., Byrne, B. A., Hodzic, E., Mapes, S., Jang, S. S., \& Magdesian, K. G. (2010a). Use of quantitative real-time PCR for the detection of Salmonella spp. in fecal samples from horses at a veterinary teaching hospital. The Veterinary Journal, 186(2), 252-255. 
Pusterla, N., Jackson, R., Mapes, S. M., Noland, J., Stenbom, R. M., \& Gebhart, C. (2010b). Lawsonia intracellularis: Humoral immune response and fecal shedding in weanling foals following intra-rectal administration of frozen-thawed or lyophilized avirulent live vaccine. The Veterinary Journal, 186(1), 110112 .

Pusterla, N., Wattanaphansak, S., Mapes, S., Collier, J., Hill, J., Difrancesco, M., \& Gebhart, C. (2010c). Oral infection of weanling foals with an equine isolate of Lawsonia intracellularis, agent of equine proliferative enteropathy. Journal of Veterinary Internal Medicine, 24(3), 622-627.

Pusterla, N., Mapes, S., \& Gebhart, C. (2012). Further investigation of exposure to Lawsonia intracellularis in wild and feral animals captured on horse properties with equine proliferative enteropathy. The Veterinary Journal, 194(2), 253-255.

Pusterla, N. \& Gebhart, C. (2013) Lawsonia intracellularis infection and proliferative enteropathy in foals. Veterinary Microbiology, 167(1-2), 34-41.

Pusterla, N., Vin, R., Leutenegger, C., Mittel, L. D., \& Divers, T. J. (2016). Equine coronavirus: An emerging enteric virus of adult horses. Equine veterinary education, 28(4), 216-223.

Pusterla, N., Vin, R., Leutenegger, C., Mittel, L. D. \& Diver, T. J. (2017) Equine coronavirus infection. In: Emerging and Re-emerging Infectious Diseases of Livestock. Springer, 121-132.

Reinemeyer, C.R (2008). Parasite control recommendation for horses during the first year of life. Proceedings of the American Association of Equine Practitioners Texas, USA, 143-154.

Reuss, S. M., Chaffin, M. K., \& Cohen, N. D. (2009). Extrapulmonary disorders associated with Rhodococcus equi infection in foals: 150 cases (19872007). Journal of the American Veterinary Medical Association, 235(7), 855-863.

Ribas, L. D. M., Moraes, C. M., Lins, L. A., Flores, E. F., \& Nogueira, C. E. W. (2009). Fatores de risco associados a doenças respiratórias em potros Puro Sangue Inglês do nascimento ao sexto mês de vida. Ciência Rural, 39(6), 1789-1794.

Rood, J. I., Adams, V., Lacey, J., Lyras, D., McClane, B. A., Melville, S. B., \& Van Immerseel, F. (2018). Expansion of the Clostridium perfringens toxinbased typing scheme. Anaerobe, 53, 5-10.

Sampieri, F., Hinchcliff, K. W., \& Toribio, R. E. (2006). Tetracycline therapy of Lawsonia intracellularis enteropathy in foals. Equine veterinary journal, 38(1), 89-92

Schumacher, J., Schumacher, J., Rolsma, M., Brock, K. V., \& Gebhart, C. J. (2000). Surgical and medical treatment of an Arabian filly with proliferative enteropathy caused by Lawsonia intracellularis. Journal of Veterinary Internal Medicine, 14(6), 630-632.

Silva, R. O. S., Moreira, F. M., Rezende, J. V., Pires, P. S., Maranhão, R. D. P. A., Palhares, M .S., \& Lobato, F. C. F. (2012). First confirmed case of Clostridium difficile-associated diarrhea in foals in Brazil. Ciência Rural, 42(3), 498-500.

Silva, R. O. S., Neves, M. S., Ribeiro, M. G., Palhares, M. S., Maranhão, R. D. P. A., \& Lobato, F. C. F. (2014). Evaluation of three enzyme immunoassays for diagnosis of Clostridium difficile-associated diarrhea in foals. Journal of Equine Veterinary Science, 34(8), 1032-1035.

Smith, D. E. \& Lawson, G. K. (2001) Lawsonia intracellularis: getting inside the pathogenesis of proliferative enteropathy. Veterinary Microbiology, 82, 331345

Slovis, N. M (2009). Foal Diarrhea: Diagnosis and treatment. In: Proceedings of the 11th International Congress of World Equine Veterinary Association Guarujá, SP, Brasil.

Slovis, N. M (2011). Infection gastrintestinal disorders. Proceedings of the 12th International Congress of World Equine Veterinary Association, Hiderabad, India.

Slovis, N. M., Elam, J., Estrada, M., \& Leutenegger, C. M. (2014). Infectious agents associated with diarrhoea in neonatal foals in central K entucky: A comprehensive molecular study. Equine Veterinary Journal, 46(3), 311-316.

Tillotson, K., Traub-Dargatz, J. L., Dickinson, C. E., Ellis, R. P., Morley, P. S., Hyatt, D. R., Magnuson, R., Riddle, T., Bolte, D. \& Salman, M. D. (2002). Population-based study of fecal shedding of Clostridium perfringens in broodmares and foals. Journal of the American Veterinary Medical Association, 220(3), 342-348.

Traub-Dargatz, J. L. \& Besser, T. E (2007). Samonellosis. In: Sellon, D.C. \& Long, M.T.(Ed.), Equine Infectious Diseases (pp. 331-345). Missouri: Saunders.

Uzal, F. A., Vidal, J. E., McClane, B. A., \& Gurjar, A. A. (2010). Clostridium perfringens toxins involved in mammalian veterinary diseases. The Open Toxinology Journal, 2, 24

Uzal, F. A. \& Diab, S. S. (2015) Gastritis, enteritis, and colitis in horses. Veterinary Clinics: Equine Practice, 31(2), $337-358$.

Vlasova, A. N., Deol, P., Sircar, S., Ghosh, S., Jacab, S., Bányai, K., Dhama, K., Amimo, J. O., Saif, L. J. \& Malik, Y. S. (2020) Animal Rotaviruses. In: Animal-Origin Viral Zoonoses (pp. 163-202). Springer: Singapore.

Ward, M. P., Alinovi, C. A., Couëtil, L. L., \& Wu, C. C. (2005). Evaluation of a PCR to detect Salmonella in fecal samples of horses admitted to a veterinary teaching hospital. Journal of veterinary diagnostic investigation, 17(2), 118-123.

Weese, J. S., Staempfli, H. R., \& Prescott, J. F. (2000). Survival of Clostridium difficile and its toxins in equine feces: implications for diagnostic test selection and interpretation. Journal of Veterinary Diagnostic Investigation, 12(4), 332-336.

Weese, J. S., Staempfli, H. R., \& Prescott, J. F. (2001). A prospective study of the roles of Clostridium difficile and enterotoxigenic Clostridium perfringens in equine diarrhoea. Equine Veterinary Journal, 33(4), 403-409. 
Research, Society and Development, v. 10, n. 4, e14710414008, 2021

(CC BY 4.0) | ISSN 2525-3409 | DOI: http://dx.doi.org/10.33448/rsd-v10i4.14008

Weese, J. S. (2007) Enteric Clostridial Infections. In: Sellon, D.C. \& LONG, M.T. Equine Infections Diseases. Saint Louis: Elsevier Saunders, cap 44, $362-$ 367.

Weese, J. S. (2008). The Gastrointestinal system. In: McAuliffe, S.B. \& SLOVIS, N.M. Color atlas of diseases and disorders of the foal (pp. 79-131) Philadelphia: Saunders.

Weese, J. S. (2020) Clostridium (Clostridioides) difficile in animals. Journal of Veterinary Diagnostic Investigation, 32(2), 213-221.

Wilson, J. H., \& Gebhart, C. J. (2008) Lawsonia proliferative enteropathy in foals: clinical features and piglet parallels. In: Proceedings of the AAEP Summer Meetings: Focus on the First Year of Life, Texas. 214-226.

Würsch, K., Hüssy, D., Koch, C., \& Oevermann, A. (2006). Lawsonia intracellularis proliferative enteropathy in a filly. Journal of Veterinary Medicine Series A, 53(1), 17-21.

Zimmel, D. (2008) Neonatal Foal Diarrhea. In: Annual Convention of the American Association Equine Practitioners: Focus Meeting- First Year of Life, Texas, USA. 207-213. 